\title{
Comparison of Scalpel and Diode Laser in Management of Gingival Enlargement: A Case Report
}

\section{ABHINAV BHASKER*1, VINITI GOEL ${ }^{2}$, DEEPT JAIN³, VIJITA MEHTA 3}

Inflammatory gingival enlargement is an excessive growth of gingival tissue due to inflammation in response to plaque accumulation. Enlargement of gingiva hampers the efficiency of daily oral hygiene practices which in turn accumulates more plaque, thus causing inflammation. Phase I therapy, consisting of scaling and root planning only reduces the inflammatory component of the enlarged gingival tissues but the fibrotic gingival enlargement remaining thereafter is then removed surgically by gingivectomy. Apart from the conventional scalpel gingivectomy, many other treatment modalities such as gingivectomy by lasers and electrocautery are now being widely used in the field of surgical periodontal therapy. This case report describes the management of gingival enlargement in relation with gingivae of maxillary teeth by administering separate treatment modalities i.e. diode laser and conventional scalpel gingivectomy.

KEYWORDS: Gingival Enlargement, Gingivectomy, Diode Laser, Scalpel

\section{INTRODUCTION}

Chronic inflammatory gingival enlargement occurs in response to plaque accumulation. The enlarged gingiva compromises proper oral hygiene maintenance. ${ }^{1}$ The first step towards management of gingival enlargement is motivating the patient regarding good oral hygiene and mechanical removal of plaque and calculus. When gingival enlargement is not resolved after successful completion of non-surgical therapy, surgical excision of gingiva is then the choice of treatment. It can be performed by using different methods i.e. by using scalpel, laser or electrocautery. Gingivectomy helps to reduce pocket depth which in turn provides access for efficient removal of remaining plaque and calculus. ${ }^{2}$ In the recent times, LASER (light amplification by stimulated emission of radiation) is widely used in periodontology for several procedures involving oral hard and soft tissues.

Advantages of laser include less intraoperative bleeding, shorter operating time and a bactericidal effect on tissues. Many surgeons have achieved effective results by using lasers in several periodontal surgical procedures like removal of excessive soft tissue, pocket epithelium elimination and detoxification of root surfaces. ${ }^{3}$

This case report is an effort to access the differences among Diode laser and scalpel in the management of gingivectomy.

\section{CASE REPORT}

A 25-year-old female patient, previously undergoing orthodontic therapy reported to the Department of Periodontology and Implantology with localized gingival enlargement in the upper anterior region. After thorough scaling, gingivectomy was planned for the patient involving the upper teeth.

To access different treatment modalities, it was decided to treat tooth number 11-16 using diode laser and tooth number 21-26 using conventional scalpel technique [figures 1(a)-(c)]. Presurgical preparation consisted of scaling, reinforcement of instructions regarding proper oral hygiene and routine blood investigations. The tissues were given local infiltration anesthesia and gingivectomy procedure was performed on teeth 21-26 with scalpel (with 15 number blade) and a wall of soft tissue was excised till the base of pocket (figure 2). Teeth 11-16 were operated with diode laser of wavelength $940 \mathrm{~nm}$, power of $3 \mathrm{~W}$, pulsed contact mode, with pulse interval and length of $0.1 \mathrm{~ms}$, scanning an area of about $1 \mathrm{~cm}^{2}$, while keeping the tip of laser perpendicular to surface of tissue (figure 3). A soaked cotton was placed to obscure the effects of laser onto the sites not treated by laser. Post-operative instructions were explained to the patient (figure 4).

At one year follow up after lock down opened up, we saw that healing was comparable with no signs of 

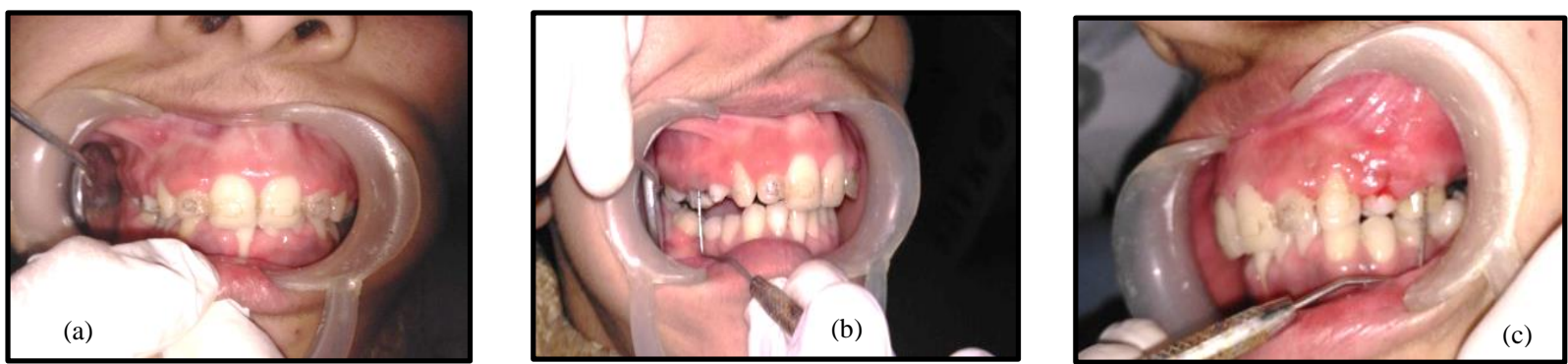

Figure 1(a). Preoperative view of maxillary gingiva; $\mathbf{1}(\mathbf{b})$. Preoperative view Right side; 1(c) Preoperative view Left side

enlargement and on examination, probing and plaque accumulation was not seen. It was also observed that after surgical procedure, patient had understood and was practicing good oral hygiene.

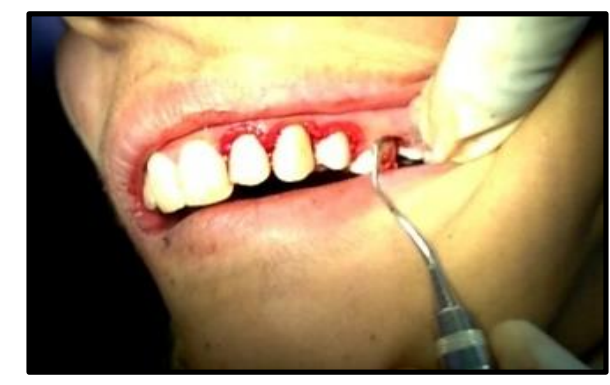

Figure 2. Gingivectomy with scalpel \& granulation tissue removal

\section{DISCUSSION}

It was observed that diode laser provides adequate hemostasis and accurate incision margins. Postoperative advantages of laser includes lack of pain, swelling and less scar tissue formation and good and uneventful wound healing. ${ }^{4}$ The wounds induced by laser heal via reparative matrix proteins synthesis. These matrix proteins in the tissues resist against laser ablation and their slow removal and replacement from the tissues causes less tissue scarring and wound contraction in laser treated areas. ${ }^{5}$

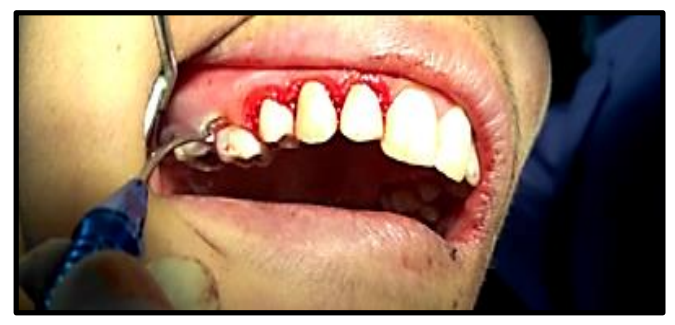

Figure 3. Gingivectomy with laser
For postoperative pain and discomfort, no significant difference was noted in the first two days, laser treated tissues generally exhibit less pain which can be attributed by the formation of protein coagulum formed on wound surface, thus acting as a biological dressing and sealing off the nerve endings. ${ }^{6}$

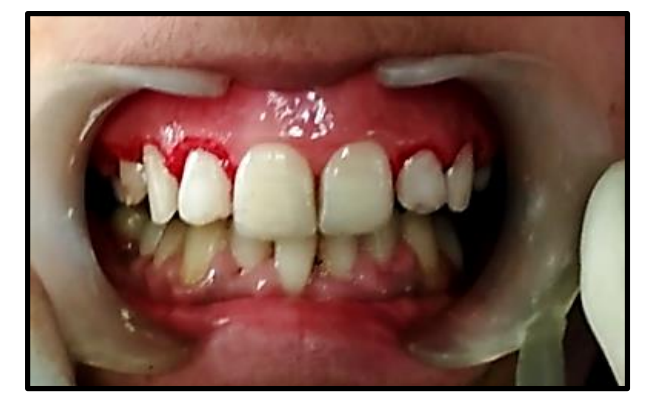

Figure 4. Immediate postoperative view

Duration of surgical procedure was less with when compared with the treatment done by scalpel. Excellent hemostasis and good vision of the field was obtained during diode laser surgery.

Though the results of laser treatment for gingivectomy are favorable, larger sample sizes are required for study in order to get more elaborate effects of laser therapy so that lasers are frequently used in several periodontal procedures, thus allowing favourable results with minimal patient morbidity. Healing after laser gingivectomy is still controversial as some researchers have reported delayed healing of tissues compared to scalpel gingivectomy ${ }^{7,8,9}$ whereas some studies shows that healing of laser wound is either similar to the scalpel or have an accelerated healing. ${ }^{10}$

\section{REFERENCES}

1. Camargo PM, Melnick PR, Pirih FQM, Lagos R, Takei $\mathrm{HH}$. Treatment of drug-induced gingival enlargement: 
Aesthetic and functional considerations. Periodontol. 2000 2001;27:131-38.

2. Palomo F, Kopczyk RA. Rationale and methods for crown lengthening. J Am Dent Assoc 1978;96:257-6o. 3. Guler B, Isler SC, Uraz A, Bozkaya S, Cetimer FD. The comparison of postoperative wound healing following different gingivectomy techniques: A randomized prospective clinical trial. Ann Med Res. 2017;26(3):3828. https://doi.org/10.5455/annalsmedres.2018.10.214 4. Romanos G, Nentwig GH. Diode laser ( $980 \mathrm{~nm}$ ) in oral and maxillofacial surgical procedures: Clinical observations based on clinical applications. J Clin Laser Med Surg. 1999;17:193-7.

5. Luomanen M, Meurman JH, Lehto VP. Extracellular matrix in healing $\mathrm{CO}_{2}$ laser incision wound. J Oral Pathol. 1987;16:322-31.

6. Schuller DE. Use of the laser in the oral cavity. Orolaryngol Clin North Am. 1990;23:31-42.
7. Amaral MB, De Avila JM, Abrew MH, Mesquita RA. Diode laser surgery versus scalpel surgery in the treatment of fibrous hyperplasia: A randomized clinical trial. Int J Oral Maxillofac Surg. 2015;44(11):1383-9. https://doi.org/10.1016/j.ijom.2015.05.015

8. Pogrel MA, Yen CK, Hansen LS. A comparison of carbon dioxide laser, liquid nitrogen cryosurgery, and scalpel wounds in healing. J Oral Surg, Oral Med, Oral Pathol. 1990;69(3):269-73.

9. Gupta G, Kumar A, Khatri M et al. Comparison of two different depigmentation techniques for treatment of hyperpigmented gingiva. J Indian Soc Periodontol 2014;18:705-9. https://doi.org/10.4103/0972$124 X .147404$

10. Mussa FE, Awazil LG, Alhamdani FY, Hussien SG. Diode laser $940 n m$ versus scalpel surgery in the treatment of chronic inflammatory gingival enlargement. J Oral Dent Res. 2019;6(2):59-69.

\section{AUTHOR AFFILIATIONS: $\left({ }^{*}\right.$ Corresponding Author)}

1. PG Student, Department of Periodontology and Oral Implantology, Bhojia Dental College \& Hospital, Baddi, Himachal Pradesh, India

2. Professor and Head of Department, Department of Periodontology and Oral Implantology, B.R.S. Dental College \& Hospital, Panchkula, Haryana, India

3. Reader, Department of Periodontology and Oral Implantology, Bhojia Dental College \& Hospital, Baddi, Himachal Pradesh, India 4. Reader, Department of Conservative Dentistry and Endodontics, B.R.S. Dental College \& Hospital, Panchkula, Haryana, India 